\title{
On Stability of Nonlinear Differential System Via Cone-Perturbing Laipunov Function Method
}

A.A.Soliman and W.F.Seyam.

Mathematics Dept., Faculty of Science, P.O.Box 13518, Benha Univ., Benha, Egypt

E-Mail:a_a_soliman@hotmail.com

\begin{abstract}
Totally equistable, totally $\phi o-$ equistable, practically - equistable ,practically $\phi_{\mathrm{o}}-$ equistable of system of differential equations are studied, Cone valued perturbing Liapunov functions method and comparison methods are our technique, Some results of these properties are given.
\end{abstract}

Keywords: Totally equistable, totally $\phi$ o - equistable, practically - equistable, practically $\phi_{0} \quad-$ equistable- Cone valued perturbing Liapunov functions method.

\section{Introduction}

Consider the non linear system of ordinary differential equations

$$
\mathrm{x}^{\prime}=\mathrm{f}(\mathrm{t}, \mathrm{x}), \quad \mathrm{x}\left(\mathrm{t}_{0}\right)=x_{0}
$$

and the perturbed system

$$
\mathrm{x}^{t}=\boldsymbol{f}(\mathrm{t}, \mathrm{x})+\mathrm{R}(\mathrm{t}, \mathrm{x}), \quad \boldsymbol{x}\left(\boldsymbol{t}_{0}\right)=x_{0} .
$$

Let $\mathrm{R}^{\mathrm{n}}$ be Euclidean $\mathrm{n}$-dimensional real space with any convenient norm $\|$.$\| , and scalar product$ $(.,.) \leq\|\cdot\|\|\cdot\|$.Let for some $\rho>0$

$$
\mathrm{S}_{\mathrm{p}}=\left\{x \in \mathrm{R}^{\mathrm{n}},\|\mathrm{x}\|<\rho\right\} .
$$

where

$$
\begin{aligned}
& \mathrm{f}, \mathrm{R} \in \boldsymbol{C}\left[\mathrm{J} \times \mathrm{S}_{\rho}, \mathrm{R}^{\mathrm{n}}\right], \mathrm{J}=[0, \infty) \text { and } \boldsymbol{c}\left[\mathrm{J} \times \mathrm{S}_{\rho}, \mathrm{R}^{\mathrm{n}}\right] \\
& \text { denotes the space of continuous } \\
& \boldsymbol{u}^{\prime}=\mathrm{g}_{1}(\mathrm{t}, \mathrm{u}) \quad \boldsymbol{u}\left(\boldsymbol{t}_{0}\right)=u_{0}, \\
& \omega^{t}=\mathrm{g}_{2}(\mathrm{t}, \omega) \quad \omega\left(t_{0}\right)=\omega_{0} \\
& \mathrm{u}^{\prime}=\mathrm{g}_{1} \text { (t. u) }+\varphi_{1} \quad \mathrm{u}\left(\mathrm{t}_{0}\right)=\boldsymbol{u}_{0} \\
& \left.\omega^{\prime}=\mathrm{g}_{2} \text { (t. } \omega\right)+\varphi_{2} \quad \omega\left(\mathrm{t}_{0}\right)=\omega_{0}
\end{aligned}
$$

(1.6)

where $\quad \mathrm{g}_{1}, \mathrm{~g}_{2} \in \mathrm{C}[\mathrm{J} \times \mathrm{R}, \mathrm{R}], \quad \varphi_{1}, \varphi_{2} \in \mathrm{C}[\mathrm{J}, \mathrm{R}]$ respectively.

The following definitions [1] will be needed in the sequal .

\section{Definition 1.1}

A proper subset $\mathrm{K}$ of $\mathrm{R}^{\mathrm{n}}$ is called a cone if (i) $\lambda K \subset K, \lambda \geq 0$. (ii) $K+K \subset K$, (iii) $\bar{K}=K,(i v) K^{0} \neq \emptyset, \quad$ (v) $K \cap(-K)=\{0\}$. where $\mathrm{K}$ and $\boldsymbol{K}^{0}$ denotes the closure and interior of $\mathrm{K}$ respectively and $\partial \mathrm{K}$ denote the boundary of $\mathrm{K}$.

\section{Definition 1.2}

The set $K^{*}=\left\{\phi \in R^{n},(\phi, x) \geq 0, x \in K\right\}$ is called the adjoint cone if it satisfies the properties of the definition 3.1 .

$\mathrm{x} \in \partial \mathrm{K}$ if $(\phi, \mathrm{x})=0$ for some $\phi \in \mathrm{K}_{0}^{*}, \mathrm{~K}_{0}=\frac{\mathrm{K}}{\{0\}}$.

\section{Definition 1.3}

A function $\mathrm{g}: \mathrm{D} \rightarrow \boldsymbol{K}, \mathrm{D} \subset \mathrm{R}^{\mathrm{n}} \quad$ is called quasimonotone relative to the cone $\mathrm{K}$ if $\mathrm{x}, \mathrm{y} \in \mathrm{D}, \mathrm{y}-\mathrm{x} \in \partial \mathrm{K}$ then there exists $\phi_{0} \in \mathrm{K}_{0}^{*}$ such that $\llbracket\left(\phi \rrbracket_{0}, \mathrm{y}-\mathrm{x}\right)=0$ and $\left(\phi_{0}, g(\mathrm{y})-g(x)\right)>0$.

\section{Definition 1.4}

A function $\mathrm{a(.)}$ is said to belong to the class $\mathcal{K}$ if

$\mathrm{a} \in\left[\mathrm{R}^{+}, \mathrm{R}^{+}\right], \mathrm{a}(0)=0$ and $\mathrm{a}(r)$ is strictly monotone increasing in $r$.

\section{Totally equistable}

In this section we discuss the concept of totally equistable of the zero solution of (1.1) using perturbing Liapuniv functions method and Comparison principle method.

We define for

$V \in C\left[\mathrm{~J} \times \mathrm{S}_{\rho}, \mathrm{R}^{\mathrm{n}}\right]$, the function $\boldsymbol{D}^{+} \mathrm{V}(\mathrm{t}, \mathrm{x}) \mathrm{b} \boldsymbol{y}$

$\sup \frac{1}{h(V(t+h, x+h(f(t, x)+R(t, x))-V(t, x)) \cdot d}$

The following definition [2-10] will be needed in the sequal.

\section{Definition 2.1}

The zero solution of the system (1.1) is said to be $\mathrm{T}_{1}-$ totally equistable (stable with respect to permanent perturbations) , if for every $\epsilon>0, \mathrm{t}_{0} \in J$ there exist two positive numbers $\delta_{1}=\delta_{1}(\epsilon)>0$ and $\delta_{2}=\delta_{2}(\epsilon)>0$ such that for every solution of perturbed equation (1.2), the inequality

$$
\left\|\mathrm{x}\left(\mathrm{t}, \mathrm{t}_{0}, x_{0}\right)\right\|<\epsilon \text { for } \mathrm{t} \geq \mathrm{t}_{0}
$$

holds ,provided that $\left\|\mathrm{x}_{-} \mathbf{0}\right\|<\delta_{-} \mathbf{1}$ and $\|\mathrm{R}(\mathrm{t}, \mathrm{x})\|<\delta_{2}$.

\section{Definition 2.2}

The zero solution of the equation (1.3) is said to be $\mathrm{T}_{1}-$ totally equistable (stable with respect to permanent perturbations) , if for every $\epsilon>0, t_{0} \in J$, there exist two positive numbers 
$\delta_{1}^{*}=\delta_{1}^{*}(\epsilon)>0$ and $\delta_{2}^{*}=\delta_{2}^{*}(\epsilon)>0$ such that for every solution of perturbed equation (1.5).the inequality

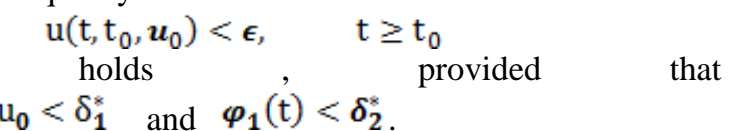

\section{Theorem 2.1}

Suppose that there exist two functions $\mathrm{g}_{1}, \mathrm{~g}_{2} \in \mathrm{C}[\mathrm{J} \times \mathrm{R}, \mathrm{R}]$ withg $\mathrm{w}_{1}(\mathrm{t}, 0)=\mathrm{g}_{2}(\mathrm{t}, 0)=0$ and there exist two Liapunov functions

$\mathrm{V}_{1} \in C\left[\mathrm{~J} \times \mathrm{S}_{\rho}, \mathrm{R}^{\mathrm{n}}\right]$ and $\mathrm{V}_{2 \eta} \in \mathrm{C}\left[J \times \mathrm{S}_{\rho} \cap \mathrm{S}_{\eta}^{\mathrm{C}}, \mathrm{R}^{\mathrm{n}}\right]$ with $\quad V_{1}(\mathrm{t}, 0)=V_{2 \eta}(\mathrm{t}, 0)=\mathbf{0} \quad$ where $S_{\eta}=\left\{x \in R^{n},\|x\|<\eta\right\}$ for $\eta>0$ and $S_{\eta}^{C}$ denotes the complement of $S_{\eta}$ satisfying the following conditions:

$\left(\mathrm{H}_{1}\right) \quad \mathrm{V}_{1}(\mathrm{t}, \mathrm{x})$ is locally Lipschitzian in $\mathrm{x}$. $D^{+} \mathrm{V}_{1}(\boldsymbol{t}, \boldsymbol{x}) \leq \mathrm{g}_{1}\left(\boldsymbol{t}, \mathrm{V}_{1}(\mathrm{t}, \mathrm{x})\right) \quad \forall(\mathrm{t}, \boldsymbol{x}) \in J \times \boldsymbol{S}_{\boldsymbol{\rho}}$. $\left(\mathrm{H}_{2}\right) \quad \mathrm{V}_{2 \eta}(\mathrm{t}, \mathrm{x}) \quad$ is locally Lipschitzian in $\mathrm{x}$ $\mathrm{b}(\|\mathrm{x}\|) \leq \mathrm{V}_{2 \eta}(\mathrm{t}, \mathrm{x}) \leq \boldsymbol{a}(\|\mathrm{x}\|) \quad \forall(\mathrm{t}, \mathrm{x}) \in J \times S_{\rho} \cap S_{\eta}^{C}$. where $a, b \in \mathcal{K}$ are increasing functions.

$\left(\boldsymbol{H}_{3}\right)$

$D^{+} V_{1}(t, x)+D^{+} V_{2 \eta}(t, x) \leq g_{2}\left(t, V_{1}(\mathrm{t}, \mathrm{x})+V_{2 \eta}(\mathrm{t}, \mathrm{x})\right) \quad \forall(t, x) \in J \times S_{\rho} \cap S_{\eta^{\prime}}^{C}$

$\left(\boldsymbol{H}_{4}\right)$ If the zero solution of (1.3) is equistable , and the zero solution of (1.4) is totally equistable

Then the zero solution of ( 1.1$)$ is totally equistable.

\section{Proof}

Since the zero solution of the system (1.4) is totally equistable, given $b(\epsilon)>0$, there exist two positive numbers $\delta_{1}^{*}=\delta_{1}^{*}(\epsilon)>0$ and $\delta_{2}^{*}=\delta_{2}^{*}(\epsilon)>0$ such that for every solution $\omega\left(\mathrm{t}, \mathrm{t}_{0}, \omega_{0}\right)$ of perturbed equation (1.6) the inequality

$$
\begin{array}{cc}
\omega\left(\mathrm{t}_{1} \mathrm{t}_{0}, \omega_{0}\right)<\epsilon_{p} & \mathrm{t} \geq \mathrm{t}_{0} \\
\text { holds } & \text { provided }
\end{array}
$$

$\omega_{0}<\delta_{1}^{*}$ and $\varphi_{2}(\mathrm{t})<\delta_{2}^{*}$.

Since the zero solution of (1.3) is equistable given $\frac{\delta_{0}(\epsilon)}{2}$ and $t_{0} \in J$, there exists $\delta=\delta\left(\mathrm{t}_{0}, \epsilon\right)>0$ such that

$$
\mathrm{u}\left(\mathrm{t}, t_{0}, u_{0}\right)<\frac{\delta_{0}(\epsilon)}{2}
$$

holds, provided that $\boldsymbol{u}_{0} \leq \boldsymbol{\delta}$

From the condition $\left(\mathrm{H}_{2}\right)$ we can find $\delta_{1}=\delta_{1}(\epsilon)>0$ such that

$$
\mathrm{a}\left(\delta_{1}\right)+\frac{\delta_{0}}{2}<\delta_{1}^{*}
$$

To show that the zero solution of (1.1) is $\mathrm{T}_{1}-$ totally equistable, it must show that for every $\epsilon>0, \mathrm{t}_{0} \in J$ there exist two positive numbers $\quad \delta_{1}=\delta_{1}(\epsilon)>0$ and $\delta_{2}=\delta_{2}(\epsilon)>0$ such that for every solution $\mathrm{x}\left(\mathrm{t}, \mathrm{t}_{0}, \boldsymbol{x}_{0}\right)$ of perturbed equation (1.2).the inequality

$\left\|\mathrm{x}\left(\mathrm{t}, \mathrm{t}_{0}, \boldsymbol{x}_{0}\right)\right\|<\boldsymbol{\epsilon}$ for $\mathrm{t} \geq \mathrm{t}_{0}$

holds ,provided that $\left\|\mathrm{x}_{-} \mathbf{0}\right\|<\delta_{-} \mathbf{1}$ and $\|\mathrm{R}(\mathrm{t}, \mathrm{x})\|<\delta_{2}$.

Suppose that this is false, then there exists a solution $x\left(t, t_{0}, x_{0}\right)$ of (1.2) with $t_{1}>t_{0}$ such that

$$
\left\|\mathrm{x}\left(\mathrm{t}_{0}, \mathrm{t}_{0}, \mathrm{x}_{0}\right)\right\|=\delta_{1}, \quad\left\|\mathrm{x}\left(\mathrm{t}_{1}, \boldsymbol{t}_{0}, x_{0}\right)\right\|=\epsilon
$$

$$
\begin{aligned}
& \delta_{1} \leq\left\|\mathrm{x}\left(\mathrm{t}, \mathrm{t}_{0}, x_{0}\right)\right\| \leq \epsilon \quad \text { for } t \in\left[\mathrm{t}_{0}, \mathrm{t}_{1}\right] \text {. } \\
& \text { Let } \quad \delta_{1}=\eta \text { and setting } \\
& \mathrm{m}(\mathrm{t}, \mathrm{x})=\boldsymbol{V}_{1}(\boldsymbol{t}, \mathrm{x})+\mathrm{V}_{2 \eta}(\boldsymbol{t}, \boldsymbol{x})
\end{aligned}
$$
in $\mathrm{x}$ for constants $\mathrm{M}_{1}$ and $\boldsymbol{M}_{2}$ respectively.

Then

$\left.D^{+} V_{1}(t, x)_{1}, 2+D^{+} V_{2 \pi}(t, x)\right)_{1}, 2 \leq D^{+} V_{1}(t, x)_{1}, 1+D^{+} V_{2 \pi}(t, x)_{1}, 1+M\|R(t, x)\|$

where $\mathrm{M}=\mathrm{M}_{1}+\mathrm{M}_{2} \quad$ From the condition $\left(\mathrm{H}_{3}\right)$ we obtain the differential inequality $\mathrm{D}^{+} \mathrm{V}_{1}(\mathrm{t}, \mathrm{x})+D^{+} V_{2 \eta}(\mathrm{t}, \mathrm{x}) \leq \mathrm{g}_{2}\left(\mathrm{t}, \mathrm{V}_{1}(\mathrm{t}, \mathrm{x})+\mathrm{V}_{2 \eta}(\mathrm{t}, \mathrm{x})\right)+\mathrm{M}\|\boldsymbol{R}(\mathrm{t}, \mathrm{x})\|$

for $t \in\left[t_{0}, t_{1}\right]$ Then we have

$\mathrm{D}^{+} \mathrm{m}(\mathrm{t}, \mathrm{x}) \leq \boldsymbol{g}_{2}(\mathrm{t}, \mathrm{m}(\mathrm{t}, \mathrm{x}))+\boldsymbol{M}\|\boldsymbol{R}(\mathrm{t}, \mathrm{x})\|$

Let $\omega_{0}=m\left(t_{0}, x_{0}\right)=v_{1}\left(t_{0}, x_{0}\right)+V_{2 \eta}\left(t_{0}, x_{0}\right)$

Applying the comparison Theorem (1.4.1) of [7 ] , it yields

$\mathrm{m}(\mathrm{t}, \mathrm{x}) \leq \boldsymbol{r}_{2}\left(\boldsymbol{t}, \mathrm{t}_{0}, \omega_{0}\right) \quad$ for $\quad \mathrm{t} \in\left[\mathrm{t}_{0}, \mathrm{t}_{1}\right]$. where $r_{2}\left(t, t_{0}, \omega_{0}\right)$ is the maximal solution of the perturbed equation (1.6)

Define $\varphi_{2}(\mathrm{t})=\mathrm{M}\|\boldsymbol{R}(\mathrm{t}, \mathrm{x})\|$

To prove that

$r_{2}\left(t, t_{0}, \omega_{0}\right)<b(\epsilon)$.

It must be show that

$\omega_{0}<\delta_{1}^{*}$ and $\varphi_{2}(\mathrm{t})<\delta_{2}^{*}$.

Choose $\mathrm{u}_{0}=\mathrm{V}_{1}\left(\mathrm{t}_{0}, \mathrm{x}_{0}\right)$. From the condition $\left(\mathrm{H}_{1}\right)$ and applying the comparison Theorem of [7 ], it yields

$\mathrm{V}_{1}(\mathrm{t}, \mathrm{x}) \leq \mathrm{r}_{1}\left(t, \mathrm{t}_{0}, \boldsymbol{u}_{0}\right)$

where $r_{1}\left(t, t_{0}, u_{0}\right)$ is the maximal solution of (1.3).

$$
\begin{aligned}
& \text { From (2.2) at } \mathrm{t}=\mathrm{t}_{0} \\
& \mathrm{~V}_{1}\left(\mathrm{t}_{0}, \mathrm{x}_{0}\right) \leq \mathrm{r}_{1}\left(\mathrm{t}_{0}, \mathrm{t}_{0}, \mathrm{u}_{0}\right)<\frac{\delta_{0}(\mathrm{e})}{2}
\end{aligned}
$$

From the condition $\left(\mathrm{H}_{2}\right)$ and (2.4), at $\mathrm{t}=\mathrm{t}_{0}$

$\mathrm{V}_{2 \eta}\left(\mathrm{t}_{0}, \mathrm{x}_{0}\right) \leq \mathrm{a}\left(\left\|\mathrm{x}_{0}\right\|\right) \leq \mathrm{a}\left(\delta_{1}\right)$

From (2.3), we get

$\omega_{0}=V_{1}\left(t_{0}, x_{0}\right)+V_{2 \eta}\left(t_{0}, x_{0}\right) \leq \frac{\delta_{0}(\epsilon)}{2}+a\left(\delta_{1}\right)<\delta_{1}^{*}$.

Since $\varphi_{2}(\mathrm{t})=\mathrm{M}\|\boldsymbol{R}(\mathrm{t}, \mathrm{x})\| \leq \boldsymbol{M} \delta_{2}=\delta_{2}^{*}$

From (2.1), we get 
Then from the condition $\left(\mathrm{H}_{2}\right),(2.4)$ and (2.7)

$\left(\mathrm{h}_{3}\right) \quad D^{+} \rrbracket\left(\phi_{0}, \mathrm{~V} \bigvee_{1}(t, x)\right)+D^{+} \rrbracket\left(\phi_{0}, V_{2 \eta}(t, \mathrm{x})\right) \leq \mathrm{g}_{2}\left(t, V_{1}(\mathrm{t}, x)+V_{2 \eta}(t, x)\right)$ for $(\mathrm{t}, \mathrm{x}) \in J \times S_{\rho}^{*} \cap S_{\eta}^{*} C$.

$\left(h_{4}\right)$ If the zero solution of (1.3) is $\phi_{0}-$ we get $\mathrm{t}=\mathrm{t}_{1}$

$\mathrm{b}(\mathrm{\epsilon})=b\left(\left\|\mathrm{x}\left(\mathrm{t}_{1}\right)\right\|\right) \leq \mathrm{V}_{2 \eta}\left(\mathrm{t}_{1}, x\left(\mathrm{t}_{1}\right)\right)<m\left(\mathrm{t}_{1}, \mathrm{x}\left(\mathrm{t}_{1}\right)\right) \leq \mathrm{r}_{2}\left(\mathrm{t}_{1}, t_{0}, \omega_{0}\right)<b(\mathrm{\epsilon})$.

This is acontradiction, then it must be $\left\|\mathrm{x}\left(\mathrm{t}, \mathrm{t}_{0}, \boldsymbol{x}_{0}\right)\right\|<\boldsymbol{\epsilon}$ for $\mathrm{t} \geq \mathrm{t}_{0}$

holds ,provided that $\left\|\mathrm{x}_{-} \mathbf{0}\right\|<\delta_{-} \mathbf{1}$ and $\|\mathrm{R}(\mathrm{t}, \mathrm{x})\|<\delta_{2}$.

Therefore the zero solution of (1.1) is totally equistable.

\section{Totally $\phi_{0}$ - equistable.}

In this section we discuss the concept of Totally $\phi_{0}-$ equistable of the zero solution of (1.1) using cone valued perturbing Liapunov functions method and Comparison principle method.

The following definition [3] will be needed in the sequal.

\section{Definition 3.1}

The zero solution of the system (1.1) is said to be totally $\phi_{0}-$ equistable ( $\phi_{0}-$ equistable with respect to permanent perturbations) ,if for every $\epsilon>0$,

$\mathrm{t}_{0} \in \mathrm{J}$ and $\phi_{0} \in \boldsymbol{K}_{0}^{*}$ there exist two positive numbers $\quad \delta_{1}=\delta_{1}(\epsilon)>0$ and $\delta_{2}=\delta_{2}(\epsilon)>0$ such that the inequality

$\left(\phi_{0}, \mathrm{x}\left(\mathrm{t}, \mathrm{t}_{0}, x_{0}\right)\right)<\epsilon$ for $\mathrm{t} \geq \mathrm{t}_{0}$

holds ,provided that $\left(\phi_{0}, \mathrm{x}_{0}\right)<\delta_{1}$ and $\|\mathrm{R}(\mathrm{t}, \mathrm{x})\|<\delta_{2}$ where $\mathrm{x}\left(\mathrm{t}, \mathrm{t}_{0}, \boldsymbol{x}_{0}\right)$ is the maximal solution of perturbed equation (1.2).

Let for some $\rho>0$

$$
S_{\rho}^{*}=\left\{x \in R^{n},\left(\phi_{0}, x\right)<\rho, \phi_{0} \in K_{0}^{*}\right\}
$$

\section{Theorem 3.1}

Suppose that there exist two functions $\mathrm{g}_{1}, \mathrm{~g}_{2} \in \mathrm{C}[\mathrm{J} \times \mathrm{R}, \mathrm{R}]_{\text {with }} \quad \mathrm{g}_{1}(\mathrm{t}, 0)=\mathrm{g}_{2}(\mathrm{t}, 0)=0$ and let there exist two cone valued Liapunov functions

$\mathrm{V}_{1} \in \boldsymbol{C}\left[\mathrm{I} \times \mathrm{S}_{\rho}^{*}, \mathrm{~K}\right]$ and $\mathrm{V}_{2 \eta} \in \mathrm{C}\left[J \times \mathrm{S}_{\rho}^{*} \cap \mathrm{S}_{\eta}^{* \mathrm{C}}, \boldsymbol{K}\right]$ with $V_{1}(\mathrm{t}, 0)=V_{2 \eta}(\mathrm{t}, 0)=0$ where

$S_{\eta}^{*}=\left\{x \in K,\left(\phi_{0}, x\right)<\boldsymbol{\eta}, \phi_{0} \in K_{0}^{*}\right\}$ for $\boldsymbol{\eta}>0$ and $S_{\eta}^{*} \mathrm{C}$ denotes the complement of $S_{\eta}^{*}$ satisfying the following conditions:

$\left(\boldsymbol{h}_{1}\right) \quad \mathrm{V}_{1}(\mathrm{t}, \mathrm{x})$ is locally Lipschitzian in $\boldsymbol{x}$ and $D^{+} \llbracket\left(\phi_{0}, V_{1}(t, x)\right) \leq \mathrm{g}_{1}\left(\mathrm{t}, \mathrm{V}_{1}(\mathrm{t}, \mathrm{x})\right)$ for $(t, x) \in J \times S_{\rho}^{*}$. $\left(\boldsymbol{h}_{2}\right) \quad \mathrm{V}_{2 \eta}(\mathrm{t}, \mathrm{x})$ is locally Lipschitzian in $\boldsymbol{x}$ and $\mathrm{b}\left(\phi_{0}, x\right) \leq \llbracket\left(\phi_{0}, \mathrm{~V}_{2 \eta}(\mathrm{t}, \mathrm{x})\right) \leq a\left(\phi_{0}, \mathrm{x}\right)$ for $\left(t, \mathrm{x}_{\mathrm{t}}\right) \in J \times S_{\rho}^{*} \cap S_{\eta}^{* C}$ (3.1) equistable, and the zero solution of (1.4)is totally $\phi_{0}-$ equistable . then the zero solution of ( 1.1 ) is totally $\phi_{0}-$ equistable.

\section{Proof}

Since the zero solution of (1.4) is totally $\phi_{0}-$ equistable, given, given $\mathrm{b}(\epsilon)>0$ there exist two positive numbers $\delta_{1}^{*}=\delta_{1}^{*}(\epsilon)>0$ and $\delta_{2}^{*}=\delta_{2}^{*}(\epsilon)>0 \quad$ such that the inequality

$$
\left(\phi_{0}, \mathrm{r}_{2}\left(\mathrm{t}, \mathrm{t}_{0}, \omega_{0}\right)\right)<\epsilon, \quad \mathrm{t} \geq \mathrm{t}_{0}
$$

holds provided that $\left(\phi_{0}, \omega_{0}\right)<\delta_{1}^{*}$ and $\varphi_{2}(\mathrm{t})<\delta_{2}^{*}$. where $\mathrm{r}_{2}\left(\mathrm{t}, \mathrm{t}_{0}, \omega_{0}\right)$ is the maximal solution of perturbed equation (1.6).

Since the zero solution of the system (1.3) is $\phi_{0}-$ equistable, given $\frac{\delta_{0}(\epsilon)}{2}$ and $t_{0} \in \mathrm{J}$ there exists $\delta=\delta\left(\mathrm{t}_{0}, \epsilon\right)>0$ such that

$$
\left(\phi_{0}, \mathrm{r}_{1}\left(\mathrm{t}, \boldsymbol{t}_{0}, \boldsymbol{u}_{0}\right)\right)<\frac{\delta_{0}(\boldsymbol{\epsilon})}{2}
$$

holds ,provided that $\mathbb{}\left(\phi_{0}, \boldsymbol{u}_{0}\right) \leq \boldsymbol{\delta}$ where $\mathrm{r}_{\mathbf{1}}\left(\mathrm{t}, \boldsymbol{t}_{0}, \boldsymbol{u}_{0}\right)$ is the maximal solution of (1.3)

From the condition $\left(\boldsymbol{h}_{2}\right)$ we can choose $\delta_{1}=\delta_{1}(\epsilon)>0$ such that

$$
\mathrm{a}\left(\delta_{1}\right)+\frac{\delta_{0}}{2}<\delta_{1}^{*}
$$

To show that the zero solution of (1.1) is $\mathrm{T}_{1}-$ totally $\phi_{0}-$ equistable, it must be prove that for every $\epsilon>0, \mathrm{t}_{0} \in \mathrm{J}$ and $\phi_{0} \in K_{0}^{*}$ there exist two positive numbers $\delta_{1}=\delta_{1}(\epsilon)>0$

and $\delta_{2}=\delta_{2}(\epsilon)>0$ such that the inequality $\left(\phi_{0}, \mathrm{x}\left(\mathrm{t}, \mathrm{t}_{0}, x_{0}\right)\right)<\epsilon$ for $\mathrm{t} \geq \mathrm{t}_{0}$

holds ,provided that $\left(\phi_{0}, \mathrm{x}_{0}\right)<\delta_{1}$ and $\|\mathrm{R}(\mathrm{t}, \mathrm{x})\|<\delta_{2}$ where $\mathrm{x}\left(\mathrm{t}, \mathrm{t}_{0}, \boldsymbol{x}_{0}\right)$ is the maximal solution of perturbed equation (1.2).

Suppose that is false, then there exists a solution $\mathrm{x}\left(\mathrm{t}, \mathrm{t}_{0}, \boldsymbol{x}_{0}\right)$ of (1.2) with $\mathrm{t}_{1}>\mathrm{t}_{0}$ such that $\left(\phi_{0}, \mathrm{x}\left(\mathrm{t}_{0}, \mathrm{t}_{0}, \mathrm{x}_{0}\right)\right)=\delta_{1}, \quad\left(\phi_{0}, \mathrm{x}\left(\mathrm{t}_{1}, \mathrm{t}_{0}, \mathrm{x}_{0}\right)\right)=\epsilon$

$\delta_{1} \leq\left(\phi_{0}, \mathrm{x}\left(\mathrm{t}, \mathrm{t}_{0}, x_{0}\right)\right) \leq \epsilon \quad$ for $\mathrm{t} \in\left[\mathrm{t}_{0}, \mathrm{t}_{1}\right]$. Let $\quad \delta_{1}=\eta$ and setting $\mathrm{m}(\mathrm{t}, \mathrm{x})=\boldsymbol{V}_{1}(\boldsymbol{t}, \mathrm{x})+\mathrm{V}_{2 \eta}(\boldsymbol{t}, \boldsymbol{x})$

Since $V_{1}(t, x)$ and $V_{2 \eta}(t, x)$ are Lipschitzian in x for constants $\mathrm{M}_{1}$ and $\boldsymbol{M}_{2}$ respectively.

Then

$$
\begin{aligned}
& \mathrm{D}^{+}\left(\phi_{0}, \mathrm{~V}_{1}(\mathrm{t}, \mathrm{x})\right)_{1} \cdot 2+\mathrm{D}^{+} \llbracket\left(\phi_{0}, \mathrm{~V} \rrbracket_{2 \eta}(\mathrm{t}, \mathrm{x})\right)_{1} \cdot 2 \\
& \leq \mathrm{D}^{+} \llbracket\left(\phi_{0}, \mathrm{~V} \rrbracket_{1}(\mathrm{t}, \mathrm{x})\right)_{1} \cdot 1+\mathrm{D}^{+}\left(\phi_{0}, V_{2 \eta}(\mathrm{t}, \mathrm{x})\right)_{1} \cdot 1+\mathrm{M}\|R(\mathrm{t}, \mathrm{x})\|
\end{aligned}
$$

where $\mathrm{a}, \mathrm{b} \in \mathcal{K}$ are increasing functions. 
where $\mathrm{M}=\mathrm{M}_{1}+\mathrm{M}_{2}$ From the condition

$\left(h_{3}\right)$ we obtain the differential inequality

$\mathrm{D}^{+} \mathrm{l}\left(\phi_{0}, \mathrm{~V}_{2}(\mathrm{t}, \mathrm{x} \mathrm{x})\right)+\mathrm{D}^{+}\left(\phi_{0}, \mathrm{~V}_{2 \eta}(\mathrm{t}, \mathrm{x})\right) \leq \mathrm{g}_{2}\left(\mathrm{t}, \mathrm{V}_{1}(\mathrm{t}, \mathrm{x})+\mathrm{V}_{2 \eta}(\mathrm{t}, \mathrm{x})\right)+M\|\mathrm{R}(\mathrm{t}, \mathrm{x})\|$

for $t \in\left[t_{0}, t_{1}\right]$ Then we have

$\mathrm{D}^{+}\left(\phi_{0}, \mathrm{~m}(\mathrm{t}, \mathrm{x})\right) \leq \mathrm{g}_{2}(\mathrm{t}, \mathrm{m}(\mathrm{t}, \mathrm{x}))+\boldsymbol{M}\|\boldsymbol{R}(\mathrm{t}, \mathrm{x})\|$

Let $\omega_{0}=\mathrm{m}\left(\mathrm{t}_{0}, \mathrm{x}_{0}\right)=\mathrm{v}_{1}\left(\mathrm{t}_{0}, \mathrm{x}_{0}\right)+\mathrm{v}_{2 \eta}\left(\mathrm{t}_{0}, x_{0}\right)$

Applying the comparison Theorem of [7], yields

$\left(\phi_{0}, \mathrm{~m}(\mathrm{t}, \mathrm{x})\right) \leq\left(\phi_{0}, \boldsymbol{r}_{2}\left(\boldsymbol{t}, \mathrm{t}_{0}, \omega_{0}\right)\right)$ for $\mathrm{t} \in\left[\mathrm{t}_{0}, \mathrm{t}_{1}\right]$.

Define $\varphi_{2}(\mathrm{t})=\mathrm{M}\|\boldsymbol{R}(\mathrm{t}, \mathrm{x})\|$

To prove that

$\mathbb{R}\left(\phi_{0}, \mathrm{r}_{2}\left(\mathrm{t}, \mathrm{t}_{0}, \omega_{0}\right)\right)<\mathrm{b}(\epsilon)$.

It must be shown that

$\mathbb{}\left(\phi_{0}, \omega \rrbracket_{0}\right)<\delta_{1}^{*}$ and $\varphi_{2}(\mathrm{t})<\delta_{2}^{*}$.

Choose $\mathrm{u}_{0}=\mathrm{v}_{1}\left(\mathrm{t}_{0}, \mathrm{x}_{0}\right)$. From the condition

$\left(\boldsymbol{h}_{1}\right)$ and applying the comparison Theorem

[7], it yields

$\mathbb{\mathbb { R }}\left(\phi_{0}, \mathrm{~V}_{1}(\mathrm{t}, \mathrm{x})\right) \leq \mathbb{}\left(\phi_{0}, \mathrm{r} \rrbracket_{1}\left(\mathrm{t}, \mathrm{t}_{0}, \mathrm{u}_{0}\right)\right)$

From (3.2) at $\mathrm{t}=\mathrm{t}_{0}$

$\left(\phi_{0}, \mathrm{~V}_{1}\left(\mathrm{t}_{0}, \mathrm{x}_{0}\right)\right) \leq \mathbb{R}\left(\phi_{0}, \mathrm{r} \rrbracket_{1}\left(\mathrm{t}_{0}, \mathrm{t}_{0}, \mathrm{u}_{0}\right)\right)<\frac{\delta_{0}(\epsilon)}{2}$

From the condition $\left(\mathrm{h}_{2}\right)$ and (3.4), at $\mathrm{t}=\mathrm{t}_{0}$

$\left(\phi_{0}, \mathrm{~V}_{2 \eta}\left(\mathrm{t}_{0}, \mathrm{x}_{0}\right)\right) \leq \mathrm{a}\left(\phi_{0}, x_{0}\right) \leq \mathrm{a}\left(\delta_{1}\right)$

(3.6)

From (3.3), we get

$\llbracket\left(\phi_{0}, \omega \rrbracket_{0}\right)=\left(\phi_{0}, V_{1}\left(\mathrm{t}_{0}, \mathrm{x}_{0}\right)\right)+\left(\phi_{0}, V_{2 \eta}\left(\mathrm{t}_{0}, \mathrm{x}_{0}\right)\right) \leq \frac{\delta_{0}(\epsilon)}{2}+a\left(\delta_{1}\right)<\delta_{1}^{*}$.

Since $\varphi_{2}(\mathrm{t})=\mathrm{M}\|\boldsymbol{R}(\mathrm{t}, \mathrm{x})\| \leq \boldsymbol{M} \delta_{2}=\delta_{2}^{*}$

From (3.1), we get

$\left(\phi_{0}, \mathrm{~m}(\mathrm{t}, \mathrm{x})\right) \leq\left(\phi_{0}, \boldsymbol{r}_{2}\left(\boldsymbol{t}, \mathrm{t}_{0}, \omega_{0}\right)\right)<\boldsymbol{b}(\epsilon)$

(3.7)

Then from the condition $\left(\boldsymbol{h}_{2}\right),(3.4)$ and (3.7) we get at $\mathrm{t}=\mathrm{t}_{1}$

$\mathrm{b}(\epsilon)=\boldsymbol{b}\left(\boldsymbol{\phi} \_0, \boldsymbol{x}\left(\mathrm{t} \_\mathbf{1}\right)\right)$

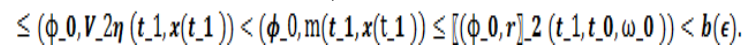

This is a contradiction, then

$\left(\phi_{0}, \mathrm{x}\left(\mathrm{t}, \mathrm{t}_{0}, x_{0}\right)\right)<\epsilon$ for $\mathrm{t} \geq \mathrm{t}_{0}$

provided that $\left(\phi_{0}, \mathrm{x}_{0}\right)<\delta_{1}$ and

$\|\mathrm{R}(\mathrm{t}, \mathrm{x})\|<\delta_{2}$ where $\mathrm{x}\left(\mathrm{t}, \mathrm{t}_{0}, x_{0}\right)$ is the maximal solution of perturbed equation (1.2).

Therefore the zero solution of (1.1) is totally $\phi_{0}-$ equistable.

\section{Practically equistable}

In this section, we discuss the concept of practically equistable of the zero solution of (1.1) using perturbing Liapunov functions method and Comparison principle method.

The following definition [5] will be needed in the sequal.
Definition 4.1

Let $0<\lambda<\mathrm{A}$ be given. The system (1.1) is said to be practically equistable if for $t_{0} \in J$ such that the inequality

$\left\|\mathrm{x}\left(\mathrm{t}, \mathrm{t}_{0}, x_{0}\right)\right\|<A \quad$ for $\mathrm{t} \geq \mathrm{t}_{0}$

holds ,provided that $\left\|\mathrm{x}_{-} \mathbf{0}\right\|<\lambda$ where $\mathrm{x}\left(\mathrm{t}, \mathrm{t}_{0}, \boldsymbol{x}_{0}\right)$ is any solution of (1.1).

In case of uniformly practically equistable ,the inequality (4.1) holds for any $\mathrm{t}_{0}$.

We define

$$
\mathrm{S}(\mathrm{A})=\left\{x \in \mathrm{R}^{\mathrm{n}} \mathrm{x}\|\mathrm{x}\| \leq \mathrm{A}, \quad \mathrm{A}>0\right\} .
$$

\section{Theorem 4.1}

Suppose that there exist two functions $\mathrm{g}_{1}, \mathrm{~g}_{2} \in \mathrm{C}[\mathrm{J} \times \mathrm{R}, \mathrm{R}]_{\text {withg }_{1}}(\mathrm{t}, 0)=\mathrm{g}_{2}(\mathrm{t}, 0)=0$ and there exist two Liapunov functions $V_{1} \in C\left[J \times S(A), R^{n}\right]$ and $V_{2 \eta} \in C\left[J \times S(A) \cap S(B)^{C}, R^{n}\right]$ with

$\mathrm{V}_{1}(\mathrm{t}, 0)=V_{2 B}(\mathrm{t}, 0)=0$

where

$\mathrm{S}(\mathrm{B})=\left\{\mathrm{x} \in \mathrm{R}^{\mathrm{n}},\|\mathrm{x}\|<\mathrm{B}, 0<\mathrm{B}<\mathrm{A}\right\}$ and $\mathrm{S}(\mathrm{B})^{\mathrm{C}}$ denotes the complement of $\mathrm{S}(\mathrm{B})$ satisfying the following conditions:

(I) $\mathrm{V}_{1}(\mathrm{t}, \mathrm{x})$ is locally Lipschitzian in $\mathrm{x}$.

$D^{+} \mathrm{V}_{1}(\boldsymbol{t}, \boldsymbol{x}) \leq \mathrm{g}_{1}\left(\boldsymbol{t}, \mathrm{V}_{1}(\mathrm{t}, \mathrm{x})\right) \quad \forall(\mathrm{t}, \mathrm{x}) \in J \times S(A)$.

(II) $V_{2 \mathrm{~B}}(\mathrm{t}, \mathrm{x})$ is locally Lipschitzian in $\mathrm{x}$.

$\mathrm{b}(\|\mathrm{x}\|) \leq \mathrm{V}_{2 \mathrm{~B}}(\mathrm{t}, \mathrm{x}) \leq a(\|\mathrm{x}\|) \quad \forall(\mathrm{t}, \mathrm{x}) \in \mathrm{J} \times \mathrm{S}(A) \cap \mathrm{S}(\mathrm{B})^{\mathrm{C}}$. where $\mathrm{a}, \boldsymbol{b} \in \mathcal{K}$ are increasing functions.

(III)

$D^{+} V_{1}(t, x)+D^{+} V_{2 \eta}(t, x) \leq g_{2}\left(t, V_{1}(t, x)+V_{2 B}(t, x)\right) \quad \forall(t, x) \in J \times S(A) \cap S(B)^{C}$.

(IV) If the zero solution of (1.3) is equistable, and the zero solution of (1.4) is uniformly practically equistable .

Then the zero solution of (1.1) is practically equistable.

\section{Proof}

Since the zero solution of (1.4) is uniformly practically equistable, given $0<\lambda_{0}<\mathrm{A}$ such that for every solution $\omega\left(\mathrm{t}, \mathrm{t}_{0}, \omega_{0}\right)$ of (1.4) the inequality

$$
\omega\left(t, t_{0}, \omega_{0}\right)<b(A)
$$

holds provided $\omega_{0} \leq \lambda_{0}$.

Since the zero solution of the system (1.3) is equistable, given $\frac{\lambda_{0}}{2}$ and $t_{0} \in \boldsymbol{R}_{+}$there exist $\delta=\delta\left(\mathrm{t}_{0}, \epsilon\right)>0$ such that for every solution $\mathrm{u}\left(\mathrm{t}, \mathrm{t}_{0}, \boldsymbol{u}_{0}\right)$ of $(1.3)$

$\mathrm{u}\left(\mathrm{t}, \mathrm{t}_{0}, \boldsymbol{u}_{0}\right)<\frac{\lambda_{0}}{2}$

holds provided that $\mathrm{u}_{0} \leq \delta$.

From the condition (II) we can find $\lambda>0$ such that

$$
a(\lambda)+\frac{\lambda_{0}}{2} \leq \lambda_{0}
$$


To show that The zero solution of (1.1) practically equistable, it must be exist $0<\lambda<\mathrm{A}$ such that for for any solution $\mathrm{x}\left(\mathrm{t}, \mathrm{t}_{0}, \boldsymbol{x}_{0}\right)$ of (1.1) the inequality

$$
\left\|\mathrm{x}\left(\mathrm{t}, \mathrm{t}_{0}, \boldsymbol{x}_{0}\right)\right\|<\boldsymbol{A} \text { for } \mathrm{t} \geq \mathrm{t}_{0}
$$

holds ,provided that $\left\|\mathrm{x}_{-} \mathbf{0}\right\|<\lambda$.

Suppose that this is false, then there exists a solution $x\left(t, t_{0}, x_{0}\right)$ of (1.1) with $t_{1}>t_{0}$ such that

$\left\|\mathrm{x}\left(\mathrm{t}_{0}, \mathrm{t}_{0}, \mathrm{x}_{0}\right)\right\|=\lambda, \quad\left\|\mathrm{x}\left(\mathrm{t}_{1}, \mathrm{t}_{0}, \mathrm{x}_{0}\right)\right\|=A$ (4.5)

$$
\begin{aligned}
& \lambda \leq\left\|\mathrm{x}\left(\boldsymbol{t}, \mathrm{t}_{0}, \boldsymbol{x}_{0}\right)\right\| \leq \boldsymbol{A} \quad \text { for } \boldsymbol{t} \in\left[\mathrm{t}_{0}, \mathrm{t}_{1}\right] . \\
& \text { Let } \lambda=\mathrm{B} \text { and setting } \\
& \mathrm{m}(\mathrm{t}, \mathrm{x})=\boldsymbol{V}_{1}(\boldsymbol{t}, \mathrm{x})+\mathrm{V}_{2 \eta}(\boldsymbol{t}, \boldsymbol{x})
\end{aligned}
$$

From the condition (III) we obtain the differential inequality for $t \in\left[t_{0}, t_{1}\right]$

$$
\mathrm{D}^{+} \mathrm{m}(\mathrm{t}, \mathrm{x}) \leq \mathrm{g}_{2}(\mathrm{t}, \mathrm{m}(\mathrm{t}, \mathrm{x}))
$$$$
\text { Let } \omega_{0}=m\left(t_{0}, x_{0}\right)=V_{1}\left(t_{0}, x_{0}\right)+V_{2 B}\left(t_{0}, x_{0}\right)
$$

Applying the comparison Theorem [7] , yields

$\mathrm{m}(\mathrm{t}, \mathrm{x}) \leq \boldsymbol{r}_{2}\left(\boldsymbol{t}, \mathrm{t}_{0}, \boldsymbol{\omega}_{0}\right) \quad$ for $\mathrm{t} \in\left[\mathrm{t}_{0}, \mathrm{t}_{1}\right]$.

where $r_{2}\left(t, t_{0}, \omega_{0}\right)$ is the maximal solution of (1.4)

To prove that

$r_{2}\left(t_{,} t_{0}, \omega_{0}\right)<b(A)$.

It must be show that $\omega_{0} \leq \lambda_{0}$.

Choose $\mathrm{u}_{0}=V_{1}\left(\mathrm{t}_{0}, \mathrm{x}_{0}\right), f$ rom the condition

(II) and applying the comparison Theorem of

[7], yields

$\mathrm{V}_{1}(\mathrm{t}, \mathrm{x}) \leq \mathrm{r}_{1}\left(\boldsymbol{t}, \mathrm{t}_{0}, \boldsymbol{u}_{0}\right)$

where $r_{1}\left(t, t_{0}, u_{0}\right)$ is the maximal solution of (1.3).

From (4.3) at $\mathrm{t}=\mathrm{t}_{0}$

$\mathrm{V}_{1}(\mathrm{t}, \mathrm{x}) \leq \mathrm{r}_{1}\left(t, \mathrm{t}_{0}, \boldsymbol{u}_{0}\right)<\frac{\lambda_{0}}{2}$

From the condition (II) and (4.5), at $\mathrm{t}=\mathrm{t}_{0}$

$\mathrm{V}_{2 \mathrm{~B}}\left(\mathrm{t}_{0}, \mathrm{x}_{0}\right) \leq \mathrm{a}\left(\left\|\boldsymbol{x}\left(\mathrm{t}_{0}\right)\right\|\right) \leq \boldsymbol{\alpha}(\mathrm{\lambda})$

From (4.4),(4.6) and(4.7), we get

$\omega_{0}=V_{1}\left(t_{0}, x_{0}\right)+V_{2 B}\left(t_{0}, x_{0}\right) \leq \lambda_{0}$

From (4.2), we get

$\mathrm{m}(\mathrm{t}, \mathrm{x}) \leq \mathrm{r}_{2}\left(\boldsymbol{t}, \mathrm{t}_{0}, \omega_{0}\right)<\boldsymbol{b}(\boldsymbol{A})$

Then from the condition(II), (4.5) and (4.8), we get at $\mathrm{t}=\mathrm{t}_{1}$

$\mathrm{b}(\mathrm{A})=b\left(\left\|\mathrm{x}\left(\mathrm{t}_{1}\right)\right\|\right) \leq V_{2 B}\left(\mathrm{t}_{1}, \mathrm{X}_{1}\right)<m\left(\mathrm{t}_{1}, \mathrm{x}\left(t_{1}\right)\right) \leq r_{2}\left(\mathrm{t}_{1}, \mathrm{t}_{0}, \omega_{0}\right)<\mathrm{b}(A)$.

This is a contradiction, then

$\left\|\mathrm{x}\left(\mathrm{t}, \mathrm{t}_{0}, \boldsymbol{x}_{0}\right)\right\|<\boldsymbol{A}$ for $\mathrm{t} \geq \mathrm{t}_{0}$

provided that $\left\|\mathrm{x} \_\mathbf{0}\right\|<\lambda$

Therefore the zero solution of (1.1) is practically equistable.

\section{5. practically $\phi_{0}-$ equistable}

In this section we discuss the concept of practically $\phi_{0}-$ equistable of the zero solution of (1.1) using cone valued perturbing Liapunov functions method and Comparison principle method.

The following definitions [6] will be needed in the sequal.

\section{Definition 5.1}

Let $0<\lambda<A$ be given. The system (1.1) is said to be practically $\phi_{0}-$ equistable, if for $\mathrm{t}_{0} \in \mathrm{J}$ and $\phi_{0} \in \boldsymbol{K}_{0}^{*}$ such that the inequality

$$
\left(\phi_{0}, x\left(\mathrm{t}_{1} \mathrm{t}_{0}, \mathrm{x}_{0}\right)\right)<\mathrm{A} \text { for } \mathrm{t} \geq \mathrm{t}_{0}
$$

holds ,provided that $\left(\phi_{0}, \mathrm{x}_{0}\right)<\lambda$

where

$\mathrm{x}\left(\mathrm{t}, \mathrm{t}_{0}, \boldsymbol{x}_{0}\right)$ is the maximal solution of (1.1)

In case of uniformly practically $\phi_{0}$ equistable ,the inequality (5.1) holds for any $\mathrm{t}_{0}$.

We define

$S^{*}(A)=\left\{x \in K,\left(\phi_{0}, x\right)<A, \phi_{0} \in K_{0}^{*}\right\}$

\section{Theorem 5.1}

Suppose that there exist two functions $\mathrm{g}_{1}, \mathrm{~g}_{2} \in \mathrm{C}[\mathrm{J} \times \mathrm{R}, \mathrm{R}]_{\text {with }}$

$\mathrm{g}_{1}(\mathrm{t}, 0)=\mathrm{g}_{2}(\mathrm{t}, 0)=0$ and let there exist two cone valued Liapunov functions

$V_{1} \in C\left[J \times S^{*}(A), K\right]$ and $V_{2 \mathrm{~B}} \in C\left[J \times S^{*}(A) \cap S^{*}(B)^{C}, K\right]$ with

$\mathrm{V}_{1}(\mathrm{t}, 0)=V_{2 B}(\mathrm{t}, 0)=0$ where

$\mathrm{S}^{*}(\mathrm{~B})=\left\{\mathrm{x} \in \boldsymbol{K},\left(\phi_{0}, \mathrm{x}_{0}\right)<\mathrm{B}, 0<\boldsymbol{B}<\boldsymbol{A}, \quad \phi_{0} \in \boldsymbol{K}_{0}^{*}\right\}$

and $\mathrm{S}^{*}(B)^{C}$ denotes the complement of $\mathrm{S}^{*}(\mathrm{~B})$

satisfying the following conditions:

(i) $\mathrm{V}_{1}(\mathrm{t}, \mathrm{x})$ is locally Lipschitzian in $\mathrm{x}$ relative to $\mathrm{K}$.

$\mathrm{D}^{+}\left(\phi_{0}, \mathrm{~V}_{1}(\mathrm{t}, \mathrm{x})\right) \leq \mathrm{g}_{1}\left(\boldsymbol{t}, \mathrm{V}_{1}(\boldsymbol{t}, \mathrm{x})\right) \quad \forall(\mathrm{t}, \mathrm{x}) \in \mathrm{J} \times \mathrm{S}^{*}(\mathrm{~A})$.

(ii) $V_{2 \mathrm{~B}}(\mathrm{t}, \mathrm{x})$ is locally Lipschitzian in $\mathrm{x}$ relative to $\mathrm{K}$.

$\mathrm{b}\left(\phi_{0}, x\right) \leq\left(\phi_{0}, \mathrm{~V}_{2 \mathrm{~B}}(\mathrm{t}, \mathrm{x})\right) \leq \mathrm{a}\left(\phi_{0}, \mathrm{x}\right) \quad \forall(\mathrm{t}, \mathrm{x}) \in \mathrm{J} \times \mathrm{S}^{*}(\mathrm{~A}) \cap \mathrm{S}^{*}(\mathrm{~B})^{C}$. where $\mathrm{a}, \mathrm{b} \in \mathcal{K}$ are increasing functions.

(iii)

$\mathrm{D}^{+}\left(\phi_{0}, \mathrm{~V}_{1}(\mathrm{t}, \mathrm{x})\right)+\mathrm{D}^{+}\left(\phi_{0}, \mathrm{~V}_{2 \mathrm{~B}}(\mathrm{t}, \mathrm{x})\right) \leq g_{2}\left(\mathrm{t}, \mathrm{V}_{1}(\mathrm{t}, \mathrm{x})+\mathrm{V}_{2 \mathrm{~B}}(\mathrm{t}, \mathrm{x})\right)$

$\forall(\mathrm{t}, \mathrm{x}) \in J \times \mathrm{S}^{*}(\mathrm{~A}) \cap \mathrm{S}^{*}(\mathrm{~B})^{\mathrm{C}}$.

(iv) If the zero solution of (1.3) is $\phi_{0}$ equistable, and the zero solution of (1.4) is uniformly practically $\phi_{(0.8)}$ equistable.

Then the zero solution of (1.1) is practically $\phi_{0}-$ equistable.

Proof

Since the zero solution of the system (1.4) is uniformly practically $\phi_{0}-$ equistable, given given $0<\lambda_{0}<\mathrm{a}$ (B) for $\mathrm{a}(\mathrm{B})>0$ such that the inequality

$\left(\phi_{0}, \mathrm{r}_{2}\left(\mathrm{t}, \mathrm{t}_{0}, \omega_{0}\right)\right)<\mathrm{a}(\mathrm{B})$

holds $\quad$ provided $\quad \mathbb{}\left(\phi_{0}, \omega \rrbracket_{0}\right) \leq \lambda_{0}$.where $\mathrm{r}_{2}\left(\mathrm{t}, \mathrm{t}_{0}, \omega_{0}\right)$ is the maximal solution of (1.4).

Since the zero solution of the system (1.3) is

$\phi_{0}-$ equistable, given $\frac{\lambda_{0}}{2}$ and $t_{0} \in R_{+}$

there exist $\delta=\delta\left(\mathrm{t}_{0}, \lambda_{0}\right)$ such that the inequality

$\left(\phi_{0}, r_{1}\left(t, t_{0}, u_{0}\right)\right)<\frac{\lambda_{0}}{2}$ 
From the condition (ii), assume that $\mathrm{a}(\mathrm{B}) \leq \boldsymbol{b}(\mathrm{A})$

also we can choose $\lambda_{1}>0$ such that

$$
a(\lambda)+\frac{\lambda_{0}}{2} \leq \lambda_{0}
$$

To show that the zero solution of (1.1) is practically $\phi_{0}-$ equistable. It must be show that

for $0<\lambda<\mathrm{A}, \quad \mathrm{t}_{0} \in \mathrm{J}$ and $\phi_{0} \in K_{0}^{*}$ such that the inequality

$$
\left(\phi_{0}, x\left(t, t_{0}, x_{0}\right)\right)<A \quad \text { for } t \geq t_{0}
$$

holds ,provided that $\left(\phi_{0}, \mathrm{x}_{0}\right)<\boldsymbol{\lambda}$ where $\mathrm{x}\left(\mathrm{t}, \mathrm{t}_{0}, \boldsymbol{x}_{0}\right)$ is the maximal solution of (1.1).

Suppose that is false, then there exists a solution $\quad \mathrm{x}\left(\mathrm{t}, \mathrm{t}_{0}, \boldsymbol{x}_{0}\right)$ of (1.1) with $\mathrm{t}_{2}>\mathrm{t}_{1}>\mathrm{t}_{0}$ such that for $\left(\phi_{0}, \mathrm{x}_{0}\right)<\lambda$ where $\lambda=\min \left(\lambda_{0}, \lambda_{1}\right)$

$$
\left(\phi_{0}, x\left(t_{1}, t_{0}, \mathrm{x}_{0}\right)\right)=\lambda_{1}, \quad\left(\phi_{0}, \mathrm{x}\left(\mathrm{t}_{2}, \mathrm{t}_{0}, \mathrm{x}_{0}\right)\right)=\boldsymbol{A}
$$

$$
\lambda_{1} \leq\left(\phi_{0}, \mathrm{x}\left(\mathrm{t}, \mathrm{t}_{0}, x_{0}\right)\right) \leq \mathrm{A} \quad \text { for } \mathrm{t} \in\left[\mathrm{t}_{1}, \mathrm{t}_{2}\right]
$$$$
\text { Let } \lambda_{1}=\mathrm{B} \text { and setting }
$$$$
\mathrm{m}(\mathrm{t}, \mathrm{x})=\boldsymbol{V}_{1}(\boldsymbol{t}, \mathrm{x})+\mathrm{V}_{2 \mathrm{~B}}(\boldsymbol{t}, \boldsymbol{x})
$$

From the condition (iii) we obtain the differential inequality

$$
\mathrm{D}^{\wedge}+\left(\phi_{-} 0, \mathrm{~m}(\mathrm{t}, \mathrm{x})\right) \leq\left(\phi_{-} 0, g_{-} 2(t, \mathrm{~m}(\mathrm{t}, \mathrm{x})) \text { for } \mathrm{t} \in\left[\mathrm{t} \_1, t_{-} 2\right]\right.
$$

$$
\omega_{0}=\mathrm{m}\left(\mathrm{t}_{1}, \mathrm{x}\left(\mathrm{t}_{1}\right)\right)=\boldsymbol{V}_{1}\left(t_{1}, x\left(\mathrm{t}_{1}\right)\right)+V_{2 B}\left(\mathrm{t}_{1}, x\left(\mathrm{t}_{1}\right)\right)
$$

Applying the comparison Theorem of [7] , yields

$\mathbb{\mathbb { }}\left(\phi \rrbracket_{0}, \mathrm{~m}(\mathrm{t}, \mathrm{x})\right) \leq\left(\phi_{0}, \boldsymbol{r}_{2}\left(\mathrm{t}, \mathrm{t}_{0}, \omega_{0}\right)\right)$

To prove that

$\left(\phi_{0}, r_{2}\left(t, t_{0}, \omega_{0}\right)\right)<\mathrm{a}(\mathrm{B})$

It must be show that

$\mathbb{R}\left(\phi_{0}, \omega_{0}\right) \leq \lambda_{0}$

Choose $\mathrm{u}_{0}=\mathrm{V}_{1}\left(\mathrm{t}_{0}, \mathrm{x}_{0}\right) \quad$ From the condition

(i) and applying the comparison Theorem [7 ] it yields

$\left(\phi_{0}, V_{1}(\mathrm{t}, x)\right) \leq\left(\phi_{0}, \mathrm{r}_{1}\left(t, \mathrm{t}_{0}, \mathrm{u}_{0}\right)\right)$

From (5.3) at $\mathrm{t}=\mathrm{t}_{1}$

$\left(\phi_{0}, V_{1}(t, x)\right) \leq\left(\phi_{0}, r_{1}\left(t, t_{0}, u_{0}\right)\right)<\frac{\lambda_{0}}{2}$

From the condition (ii) and (5.6), at $\mathrm{t}=\mathrm{t}_{1}$ $\left(\phi_{0}, \mathrm{~V}_{2 \mathrm{~B}}\left(\mathrm{t}_{1}, \mathrm{x}\left(\mathrm{t}_{1}\right)\right)\right) \leq\left(\phi_{0}, \boldsymbol{x}\left(\boldsymbol{t}_{1}\right)\right) \leq \boldsymbol{a}\left(\lambda_{1}\right)$

From (5.5),(5.8) and(5.9), we get

$\phi_{0}, V_{2 \mathrm{~B}}\left(\mathrm{t}_{1}, \boldsymbol{x}\left(\mathrm{t}_{1}\right)\right) \leq \lambda_{0}$

From (5.2), we get
$\left(\mathbb{Q}\left(\phi \rrbracket \_, \mathrm{m}(\mathrm{t}, x)\right) \leq\left(\phi \_0, r_{-} 2\left(t, \mathrm{t} \_0, \omega_{-} 0\right)\right)<a(B) \quad(5.10)\right.$

Then from the condition (ii), ,(5.4), (5.6) and (5.10), we get at $\mathrm{t}=\mathrm{t}_{2}$

$$
\begin{aligned}
\mathrm{b}(\mathrm{A}) & =\boldsymbol{b}\left(\phi_{0}, \mathrm{x}\left(\mathrm{t}_{2}\right)\right) \\
& \leq\left(\phi_{-} \mathbf{0}_{\boldsymbol{m}} \boldsymbol{m}\left(\boldsymbol{t}_{-} 2, \boldsymbol{x}\left(\mathrm{t}_{-} 2\right)\right)\right. \\
& <\left(\phi_{0}, \mathrm{r}_{2}\left(\boldsymbol{t}_{2}, \mathrm{t}_{0}, \omega_{0}\right)\right) \\
& <\mathrm{a}(\mathrm{B}) \\
& \leq \mathrm{a}(\mathrm{A}) .
\end{aligned}
$$

which leads to a contradiction, then it must be $\left(\phi_{0}, \mathrm{x}\left(\mathrm{t}, \mathrm{t}_{0}, \mathrm{x}_{0}\right)\right)<\mathrm{A} \quad$ for $\boldsymbol{t} \geq \boldsymbol{t}_{0}$

holds ,provided that $\left(\phi_{0}, \mathrm{x}_{0}\right)<\lambda \quad$ Therefore the zero solution of (1.1) is practically $\phi_{0}-$ equistable.

\section{References}

[1] E.P.Akpan, O.Akinyele ,On $\phi_{0}-$ stability of comparison differential systems J.Math.Anal. Appl. Vol.164, pp.307-324, 1992.

[2] M.M.A.El Sheikh, A.A.Soliman, M.H.AbdAlla ,On Stability of non linear systems of ordinary differential equations, Applied Mathematics and Computation, vol.113, pp.175-198, 2000.

[3] A.A.Soliman, On Total $\phi_{0}-$ stability Of Non linear Systems Of Differential Equations.Applied Mathematics and Computation, vol.130, pp.29-38, 2002.

[5] A.A.Soliman, On Total Stability Of Perturbed System Of Differential Equations. Applied Mathematics Letters 16, pp.1157-1162, 2003.

[6] J.O.Adeyeye, On Cone-Valued Lyapanov Functions and Stability in Two Measures For Integro-Differential Systems. Nonlinear Analysis 47 (2001) 4835-4843.

[7] A.A.Soliman, On Practical Stability of Perturbed Differential Systems. AppliedMathematics and Computation, vol.163, pp.1055-1060, 2005.

[8] V.Lakshmikantham, S.Leela, differential and Integeral Inequalities , AcademicPress, New York, Vol.I, 1969.

[9] V.Lakshmikantham, S.Leela, differential and Integeral Inequalities , Academic Press,New York, Vol.II, 1969.

[10] V.Lakshmikantham, S.Leela,On perturbing Liapunov functions, J. Systems Theory, vol.10, pp.85-90, 1976. 